\title{
PROPERTIES OF DOUBLE DOWEL JOINTS CONSTRUCTED OF MEDIUM DENSITY FIBERBOARD
}

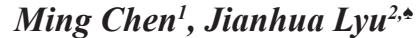

In memoriam of Dr. Thomas C. MANNES

\begin{abstract}
The objective of this study is to determine optimum parameters for double dowels in medium density fiberboard components, and the maximum value of the strength of joints loaded in tension and compression bending. This study analyzes dowel diameter, clearance or interference fit value, and dowel spacing by using the orthogonal experiment method. Optimum parameters for double dowels in medium density fiberboard component structures were obtained by orthogonal experiment and verified by simulation using ANSYS finite element analysis software. Experimental and simulation-based results revealed that the optimal parameters for double dowel joints with maximum tensile strength were a dowel diameter of $10 \mathrm{~mm}$, an interference fit of $0,20 \mathrm{~mm}$, and a spacing of $64 \mathrm{~mm}$. The optimal parameters for double dowel joints with maximum bending strength were a dowel diameter of $10 \mathrm{~mm}$, an interference fit of $0,10 \mathrm{~mm}$ and a spacing of $48 \mathrm{~mm}$.
\end{abstract}

Keywords:Finiteelementanalysis,jointparameter,jointstrength,mechanicalproperties,optimization.

\section{INTRODUCTION}

Most structural failures of panel furniture are resulted from the failures in the structure node joints during the panel furniture use, which implied that attentions should be paid to improve the mechanical performance of the structure node joints to prevent future failures as much as possible (Mayo 2015). Dowels play an important role in the overall quality of the panel furniture, and they are also the most commonly used furniture connectors (Altinok et al. 2009). The processing of dowels is much easier than that of tenons, and the connection strength of dowels is also comparable with other connectors (Liu 1993). Therefore, most global furniture manufacturers have been somewhat favored to dowel joints other than rectangular tenon joints in the furniture production. Dowels play a guiding and positioning role for eccentric connection parts in panel furniture, but otherwise play a weak role in regards to structure performance. In actual production, designers and workers usually choose dowel specifications based on experience rather than relevant analysis with taking the furniture component shape, size, and structural strength into consideration, which may result in the failure of furniture structure and the waste of material.

Dowel joints made of wood or wood-based panels have been prepared and used in several

\footnotetext{
${ }^{1}$ Associate professors, Department of Product Design, College of Forestry, Sichuan Agricultural University, Chengdu, China. chenming@sicau.edu.cn

${ }^{2}$ Associate professors, Department of Product Design, College of Forestry, Sichuan Agricultural University, Chengdu, China.

•Corresponding author: 1jh@sicau.edu.cn

Received: 14.05.2017 Accepted: 02.02.2018
} 
studies, and the influence of dowel parameters such as dowel diameter and its embedment depths on the furniture structural properties such as bending and tensile strength was examined. For example, the bending moment resistance of single-dowel corner joint was dramatically increased as the dowel diameter increased from 1/4 inch to 3/8 inch (Zhang and Eckelman 1993). Moreover the pulling resistance of dowel joints was also significantly increased as the dowel diameter and the embedment depth increased (Dong and Shao 2007). Meanwhile, the influence of connection parameters such as dowel spacing on the structural properties was also elucidated, and the results showed that the maximum strength of individual dowel was achieved when the dowels were spaced at least 3 inches apart from multi-dowel corner joints (Zhang and Eckelman 1993). In order to investigate the influence of roughness and adhesive added to the joint surface on the structural properties, the bending strength of case joints constructed with multiple fasteners including dowels and screws were conducted, and the results indicated that with adhesive added to the joint area, joints exhibited a constructed strength that exceeded the bonding strength of the board itself (Liu and Eckelman 1998). Some researches are conducted on the influence of adhesives and additives used on joint surface on tension and bending strength of joints, which found that design of joints and type of adhesive could affects joint performance (Bardak et al. 2017, Abdolzadeh et al. 2015. ).

The results of the effect of friction between dowels and the surrounding timber showed that the load-bearing capacity of a single dowel-type joint was increased with improving the surface roughness of the dowels (Sjödin et al.2008). Generally, the friction increases with the increase of roughness, in fact, with the real contact area. The bending strength and moment-rotation characteristics of T-type and twopin type dowel joints that used to construct different basic structural materials such as red oak, yellowpoplar, southern pine plywood, aspen engineered strand lumber, and particleboard were determined in order to evaluate the influence of basic material on the performance of dowel joints connection. The results showed that dowel joints constructed with red oak and plywood had higher bending strength, and those with the particleboard showed the weakest bending resistance. No significant differences in bending strength of joints between oak and plywood were observed (Zhang et al.2001).

With the rapid development of computer and related analysis techniques, Finite Element Analysis (FEA) has been applied to aeronautical, biomechanical, automotive, and many other industries to determine the stresses and strains in complicated mechanical systems (Dar et al. 2002). Meanwhile, FEA is also suitable for analyzing plastic and elastic deformation of objects identifying areas that prone to damage and failure. FEA has been also applied to the modeling and simulation in furniture structure analysis (Nicholls and Crisan 2002, Apay 2012, Smardzewski 1998, Ke et al. 2016, Smardzewski et al. 2015), and research on wood products evaluation using FEA was also proposed (Mackerle 2005). However, few research has been performed on optimal dowel diameter, clearance or interference fit value, and dowel spacing for joints constructed of 18-mm-thick MDF were ascertained, and experimental results were verified by finite element analysis simulation. Until now, there is no relevant standard and regulation for dowel joint of furniture structure, it is very important to study the structural properties of furniture assembled by dowel joints by experimental and simulation measures to define optimal geometrical parameters.

The aims of this study are (1) to determine the effects of tension and compression bending failure load behavior of double dowels joints in medium density fiberboard components, (2) to determine the optimum dowel spacing, dowel diameter and clearance or interference fit for double dowels joints in medium density fiberboard components, (3) to determine the optimum parameters for double dowels joints in medium density fiberboard component structures by simulation using ANSYS finite element analysis software.

\section{MATERIALS AND METHODS}

\section{Materials}

Japanese white birch (Betula platyphylla) obtained from Heilongjiang Province, China was used to prepare the dowels. The average moisture content, density and modulus of elasticity (MOE) of the birch wood were determined to be $12,93 \% ; 620 \mathrm{~kg} / \mathrm{m}^{3}$ and $5090 \mathrm{MPa}$, respectively. Dowels with sizes of $6 \times 40 \mathrm{~mm}, 8 \times 40 \mathrm{~mm}$ and $10 \times 40 \mathrm{~mm}$ (diameter $\times$ length) were prepared from the above mentioned 
birch wood, respectively. The $18 \mathrm{~mm}$-thickness medium density fiberboard (MDF) used in this study was purchased from Chengdu, China. The moisture content, density, and MOE of the MDF were $7,4 \% ; 710 \mathrm{~kg} / \mathrm{m}^{3}$, and $3035 \mathrm{MPa}$, respectively. The paragraphs of the dowels and MDF are presented in Figure 1.

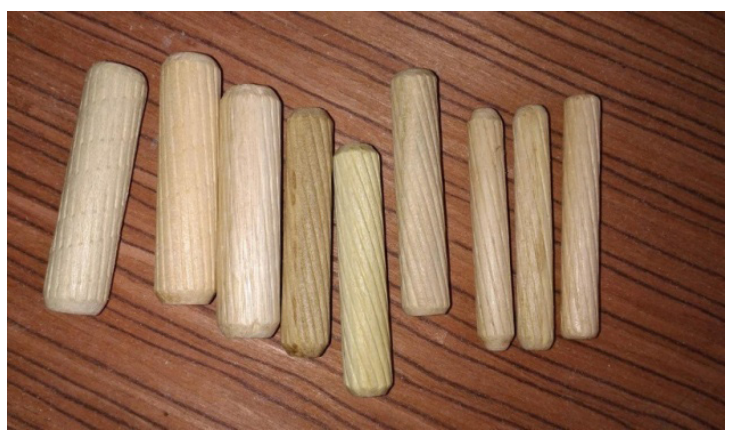

Figure 1. Shapes of dowels used in this study.

\section{Methods}

Orthogonal experimental design is an efficient method for the analysis of multi-factor and multilevel problems. The four major factors in this study included joint type, dowel diameter, dowel spacing, and clearance or interference fit (gap or overlap between dowel and MDF). For each factor, three levels were set. The experiment performs for the tensile strength resistance and bending strength resistance that designed according to the $\mathrm{L}_{9}\left(3^{4}\right)$ are presented in Table 1 and Table 2. All the tests were performed 6 times, and the average and standard deviation were taken.

Table 1. Orthogonal experiment table for tensile strength resistance.

\begin{tabular}{|c|c|c|c|}
\hline Trial No. & Dowel diameter $(\mathrm{mm})$ & Gap or overlap $(\mathrm{mm})$ & Dowel spacing $(\mathrm{mm})$ \\
\hline 1 & 6 & $+0,2$ & 32 \\
\hline 2 & 8 & 0 & 32 \\
\hline 3 & 10 & $-0,2$ & 32 \\
\hline 4 & 6 & 0 & 48 \\
\hline 5 & 8 & $-0,2$ & 48 \\
\hline 6 & 10 & 0,2 & 48 \\
\hline 7 & 6 & $-0,2$ & 64 \\
\hline 8 & 8 & 0,2 & 64 \\
\hline 9 & 10 & 0 & 64 \\
\hline
\end{tabular}

Table 2. Orthogonal experiment table for bending strength resistance.

\begin{tabular}{|c|c|c|c|}
\hline Trial No. & Dowel diameter $(\mathrm{mm})$ & Gap or overlap $(\mathrm{mm})$ & Dowel spacing $(\mathrm{mm})$ \\
\hline 1 & 6 & $+0,1$ & 16 \\
\hline 2 & 8 & 0 & 16 \\
\hline 3 & 10 & $-0,1$ & 16 \\
\hline 4 & 6 & 0 & 48 \\
\hline 5 & 8 & $-0,1$ & 48 \\
\hline 6 & 10 & 0,1 & 48 \\
\hline 7 & 6 & $-0,1$ & 80 \\
\hline 8 & 8 & 0,1 & 80 \\
\hline 9 & 10 & 0 & 80 \\
\hline
\end{tabular}


The general configuration of specimens and the schematic diagram for T-shaped joints in tensile strength tests is shown in Figure 2, and that for L-shaped joints in bending strength tests is shown in Figure 3. Each specimen was consisted of two principal structural members, i.e., the 18-mm-thick MDF and the dowels.

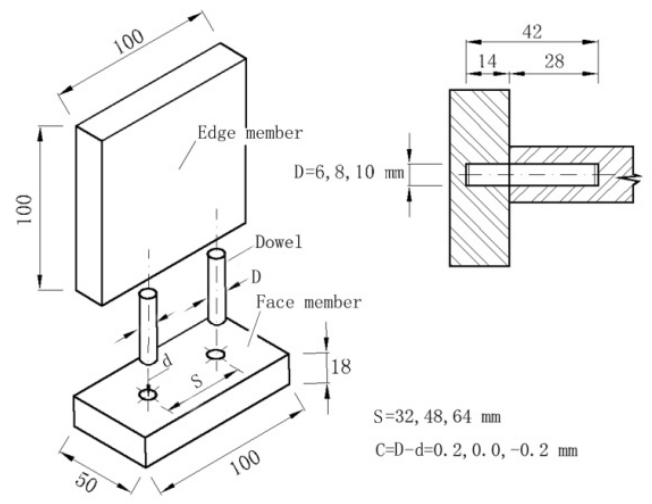

(a)

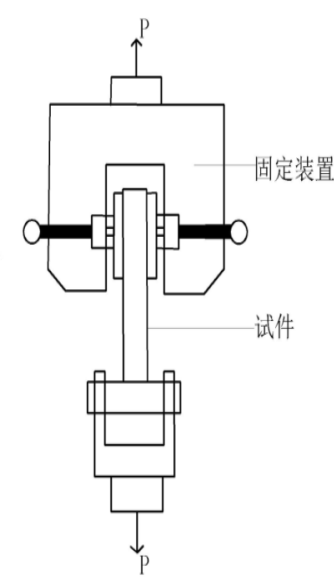

(b)

Figure 2. Typical configuration of the specimen (a) and schematic diagram of tensile strength loading in T-shaped joints tests(b). (unit: $\mathrm{mm}$ ).

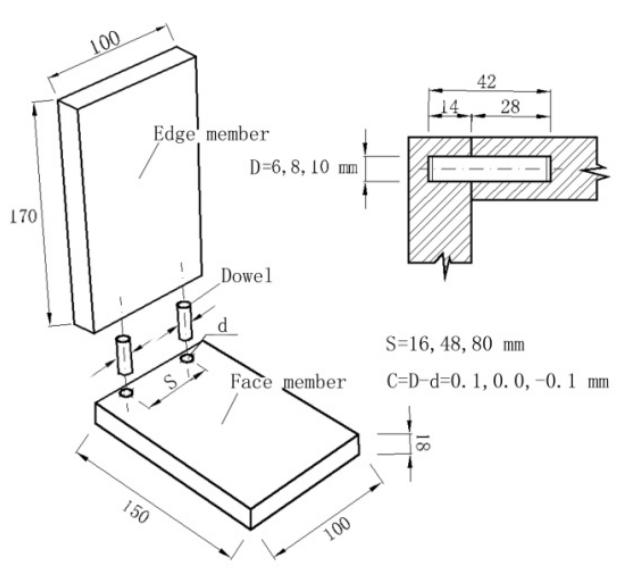

(a)

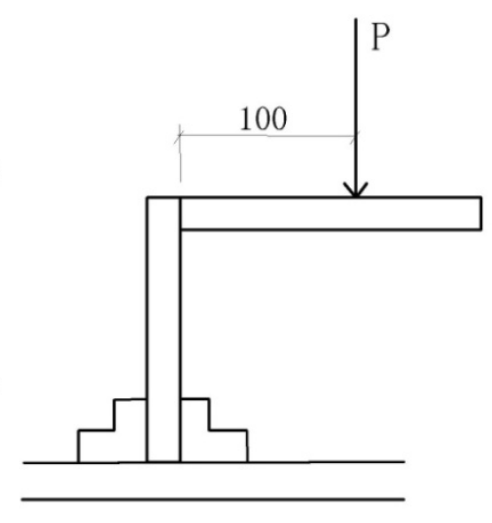

(b)

Figure 3. Typical configuration of the specimen (a) and schematic diagram of bending strength loading in L-shaped joints tests (b) unit: $\mathrm{mm}$

The tensile and bending strength was determined in accordance with GB/T 15777-1995 and GB/T 1928-2009 (China National Standard System (GB) 1995 and China National Standard System (GB) 2009). The tests were conducted by using a Reger microcomputer-controlled electronic universal testing machine (Shenzhen Reger Instrument Co., Ltd. Shenzhen, China). The rate of loading was $10 \mathrm{~mm} / \mathrm{min}$, loading continued until a non-recoverable drop-off in load occurred. Unit in $\mathrm{N}$ and $\mathrm{mm}$ were expressed the load and displacement values, respectively. The load and displacement values were obtained from a load-displacement diagram. Linear regression analysis was applied between displacement and corresponding loading to calculate the relationship between deflection and loading. Correlation coefficient $\mathrm{R}^{2}$ is calculated by the linear regression diagram, and verifies the reliability of 
the experimental data.

\section{RESULTS AND DISCUSSION}

\section{Tensile strength tests}

The tensile strength results for dowel-MDF T-shaped joints with respect to changes in dowel spacing, dowel diameter, and gap or overlap are presented in Table 3. The 8th trial had the highest tensile strength with highest standard deviation, while the $5^{\text {th }}$ trial had the lowest tensile strength.

Table 3. Orthogonal experiment results of tensile strength tests.

\begin{tabular}{|c|c|}
\hline Trial No. & $\begin{array}{c}\text { Maximum Load of Tensile } \\
\text { Strength Test }(\text { Mean } \pm \text { SD) }\end{array}$ \\
\hline 1 & $705,41 \pm 47,98$ \\
\hline 2 & $799,72 \pm 115,57$ \\
\hline 3 & $641,91 \pm 50,71$ \\
\hline 4 & $702,86 \pm 115,00$ \\
\hline 5 & $597,78 \pm 115,89$ \\
\hline 6 & $1125,70 \pm 123,90$ \\
\hline 7 & $739,25 \pm 101,62$ \\
\hline 8 & $1142,68 \pm 248,64$ \\
\hline & $1056,36 \pm 198,47$ \\
\hline
\end{tabular}

Table 4. Analysis of variance in tensile strength between different experiment tests.

\begin{tabular}{|l|r|r|r|r|r|}
\hline Source & $\begin{array}{c}\text { Type III Sum of } \\
\text { Squares }\end{array}$ & \multicolumn{1}{c|}{ df } & Mean Square & \multicolumn{1}{c|}{ F } & \multicolumn{1}{c|}{ Sig. } \\
\hline Corrected Model & $2118806,662^{\mathrm{a}}$ & 6 & 353134,444 & 17,686 & 0,000 \\
\hline Intercept & 37616740,715 & 1 & 37616740,715 & 1883,989 & 0,000 \\
\hline Dowel spacing & 644104,607 & 2 & 322052,304 & 16,130 & 0,000 \\
\hline Gap or overlap & 885363,808 & 2 & 442681,904 & 22,171 & 0,000 \\
\hline Dowel diameter & 589338,247 & 2 & 294669,123 & 14,758 & 0,000 \\
\hline Error & 938427,329 & 47 & 19966,539 & & \\
\hline Total & 40673974,706 & 54 & & & \\
\hline Corrected Total & 3057233,991 & 53 & & & \\
\hline
\end{tabular}

According to the analysis of variance as presented in Table 4, all the three factors of dowel spacing, dowel diameter, and gap or overlap have significant effect on the tensile strength for dowel-MDF $\mathrm{T}$-shaped joints $(\mathrm{P}<0,01)$. The results of mean square or $\mathrm{F}$ value analysis showed that the influence of factors on the tensile strength was in the order of gap or overlap $>$ dowel spacing $>$ dowel diameter, which is similar to the findings in other study (He 2008). 


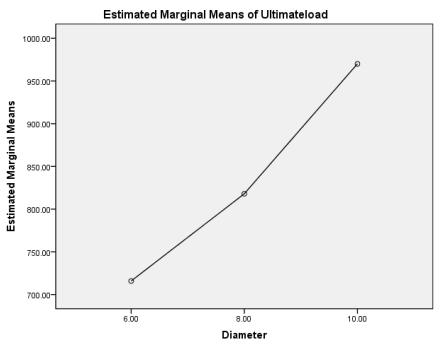

(a)

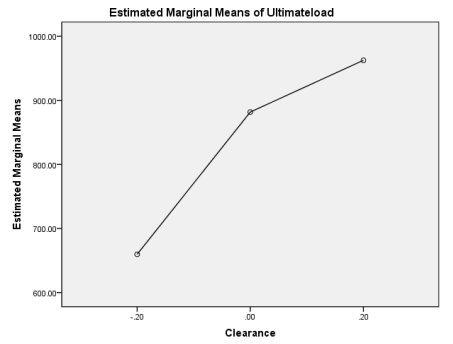

(b)

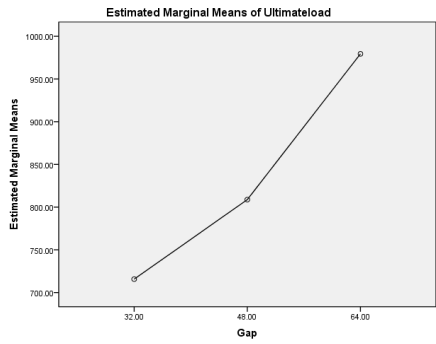

(c)

Figure 4. Estimated marginal means line charts of tensile strength under the influence of dowel diameter(a), gap or overlap between dowel and $\mathrm{MDF}(\mathrm{b})$ and dowel spacing(c).

Figure 4 shows the effect of factor levels on the tensile strength. As presented in Figure 5a, the tensile strength increased with the dowel diameter and reached the maximum at the dowel diameter of $10 \mathrm{~mm}$. The Duncan' test results showed that significant differences in tensile strength between three different diameter levels were found at 0,05 level. This result was consistent with the conclusions of other researchers (Dong and Shao 2007, Chen 2013). Tensile strength also showed an increasing trend with respect to gap or overlap between dowel and MDF, which means that the transition from clearance fit to interference fit, will result in the increasing in tensile strength. Meanwhile, the increment in tensile strength when the gap was from $-0,20 \mathrm{~mm}$ to $0,00 \mathrm{~mm}$ was larger than that from $0,00 \mathrm{~mm}$ to $+0,02 \mathrm{~mm}$ which is consistent with the conclusions of other researchers (Chen 2013, Eckelman 1970). No significant difference in tensile strength existed between $0,20 \mathrm{~mm}$ and $0,00 \mathrm{~mm}$ clearance, while the differences between the $-0,20 \mathrm{~mm}$ clearance and the $0,20 \mathrm{~mm}$ and $0,00 \mathrm{~mm}$ were significant. This result indicated that the changes in gap between dowels and MDF will result in a significant influence in the tensile strength. Similarly, tensile strength obviously increased with the dowel spacing and reached the maximum at the spacing of $64 \mathrm{~mm}$. This result showed disagreement with other findings (Chen 2013, Eckelman 1970). Significant difference in tensile strength between the $64,00 \mathrm{~mm}$ spacing group and $32,00 \mathrm{~mm}$ spacing group. Based on the results from the tensile strength tests, it can be drawn that the optimum parameters for double dowel T-shaped joints constructed of medium density fiberboard are of $10 \mathrm{~mm}$ diameter dowels $0,2 \mathrm{~mm}$ in overlap between dowel and MDF, and $64 \mathrm{~mm}$ dowel spacing.

\section{Bending strength tests}

The bending strength results for dowel-MDF L-shaped joints with respect to changes in dowel spacing, dowel diameter, and gap or overlap are presented in Table 5.The 6th trial had the highest bending strength, while the 7 th trial had the lowest bending strength. 
Table 5. Orthogonal experiment results of bending strength tests.

\begin{tabular}{|c|c|}
\hline Trial No. & $\begin{array}{c}\text { Maximum Load of Bending } \\
\text { Strength Test }(\text { Mean } \pm \text { SD) }\end{array}$ \\
\hline 1 & $84,45 \pm 19,30$ \\
\hline 2 & $114,43 \pm 11,87$ \\
\hline 3 & $95,20 \pm 20,40$ \\
\hline 4 & $83,34 \pm 14,69$ \\
\hline 5 & $129,82 \pm 19,67$ \\
\hline 6 & $201,56 \pm 19,44$ \\
\hline 7 & $82,36 \pm 8,70$ \\
\hline 8 & $122,98 \pm 18,83$ \\
\hline 9 & $108,54 \pm 26,87$ \\
\hline
\end{tabular}

Table 6. Analysis of variance in bending strength between different experiment tests Dependent Variable: Bending strength.

\begin{tabular}{|l|r|r|r|r|r|}
\hline Source & $\begin{array}{c}\text { Type III Sum of } \\
\text { Squares }\end{array}$ & \multicolumn{1}{|c|}{ df } & Mean Square & F & \multicolumn{1}{c|}{ Sig. } \\
\hline Corrected Model & $56813,639^{\text {a }}$ & 6 & 9468,940 & 17,294 & 0,000 \\
\hline Intercept & 697232,089 & 1 & 697232,089 & 1273,452 & 0,000 \\
\hline Dowel spacing & 16741,960 & 2 & 8370,980 & 15,289 & 0,000 \\
\hline Dowel diameter & 26157,880 & 2 & 13078,940 & 23,888 & 0,000 \\
\hline Gap or overlap & 13913,798 & 2 & 6956,899 & 12,706 & 0,000 \\
\hline Error & 25733,136 & 47 & 547,514 & & \\
\hline Total & 779778,864 & 54 & & & \\
\hline Corrected Total & 82546,775 & 53 & & \\
\hline
\end{tabular}

According to the analysis of variance as presented in Table 6, all the three factors of dowel spacing, dowel diameter, and gap or overlap have significant effect on the bending strength for dowel-MDF T-shaped joints $(\mathrm{P}<0,01)$. The results of mean square or $\mathrm{F}$ value analysis showed that the influence of factors on the bending strength was in the order of gap or dowel diameter $>$ dowel spacing $>$ overlap, which is similar to the findings in other study ( He 2008).

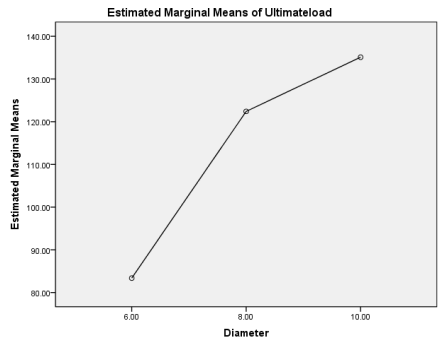

(a)

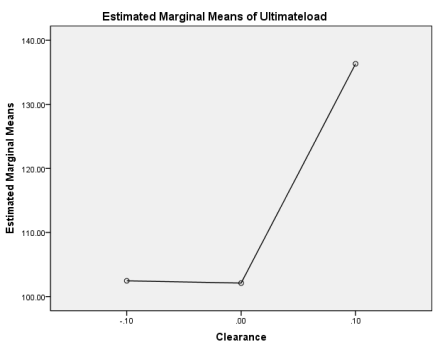

(b)

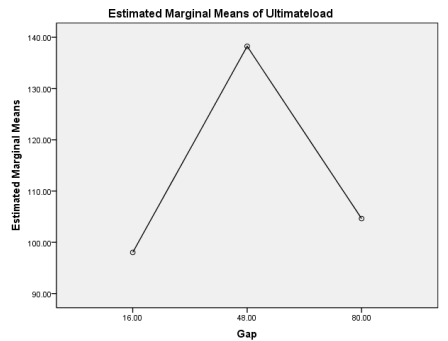

(c)

Figure 5. Estimated marginal means line charts of bending strength under the influence of dowel diameter(a), gap or overlap between dowel and $\mathrm{MDF}(\mathrm{b})$ and dowel spacing(c).

Figure 5 shows the effect of factor levels on the bending strength. As presented in Figure 5a, the bending strength increased with the dowel diameter and reached the maximum at the dowel diameter of $10 \mathrm{~mm}$. When diameter increased from $6,00 \mathrm{~mm}$ to $8,00 \mathrm{~mm}$ bending strength increased rapidly. When the diameter increased from $8,00 \mathrm{~mm}$ to $10,00 \mathrm{~mm}$ the rate of bending strength increase slowed down. 
The Duncan' test results showed that significant differences in bending strength between three different diameter levels were found at 0,05 level. This result was consistent with the conclusions of other researchers (Dong and Shao 2007, Chen 2013). Bending strength also showed a significantly increasing trend with respect to gap or overlap between dowel and MDF from $0,00 \mathrm{~mm}$ to $0,10 \mathrm{~mm}$ which means that the transition from clearance fit to interference fit, will result in the increasing in bending strength. Meanwhile, no significant difference in bending strength existed between $0,00 \mathrm{~mm}$ and $-0,10 \mathrm{~mm}$ clearance, while the differences between the $0,10 \mathrm{~mm}$ overlap and the $0,00 \mathrm{~mm}$ and $-0,10 \mathrm{~mm}$ gap were significant, which is consistent with the conclusions of other researchers (Chen 2013, Eckelman 1970). This result indicated that the changes in gap between dowels and MDF might produce some effects on the bending strength, particularly there is a overlap between dowels and MDF. Dissimilarly, bending strength obviously increased with the dowel spacing and reached the maximum at the spacing of $48,00 \mathrm{~mm}$ fracturing of dowels and decreased bending strength occurs when dowel spacing is greater than $48,00 \mathrm{~mm}$. This shows that bending moment has a certain influence on bending strength when dowel spacing is small, so that the joint has a smaller bending moment and can resist smaller external forces. This result showed agreement with other findings (Dong and Shao 2007, Chen 2013, Eckelman 1970). No significant difference in bending strength between the $16,00 \mathrm{~mm}$ spacing group and 80,00 $\mathrm{mm}$ spacing group. Based on the results from the bending strength tests, it can be drawn that the optimum parameters for double dowel L-shaped joints constructed of medium density fiberboard are of $10 \mathrm{~mm}$ diameter dowels, $0,1 \mathrm{~mm}$ in overlap between dowel and MDF, and $48 \mathrm{~mm}$ dowel spacing.

\section{VERIFICATION BASED ON ANSYS SOFTWARE}

ANSYS and AutoCAD software were both used in this study. The 3D geometric test model is built using AutoCAD software. The model is then imported into ANSYS software to calculate and analyze. Research and analysis of double dowel L-shaped and T-shaped joints constructed of medium density fiberboard first need to solve for structural characteristics, including shape, boundary, and working conditions. Then the geometric model was preliminarily established, including shape, connection components, material and load. In order to simulate the characteristics of anisotropic materials like Japanese white birch wood dowels in axial, radial and tangential directions, the SOLID45 function in ANSYS was selected. This function is set as a model body with the movement degree of freedom in three-dimensional space, and the element nodes could move freely in three-dimensional space. Some physical and mechanical properties of MDF and the orthotropic properties of Japanese white birch wood utilized for analysis using FEA were experimentally determined in previous studies, which are shown in Table 7.

Table 7. Density, Modulus of elasticity, Poisson's ratio, Shear modulus of MDF and Japanese white birch wood.

\begin{tabular}{|c|c|c|c|c|c|c|c|c|c|c|}
\hline Material & $\begin{array}{c}\text { Density } \\
\left(\mathrm{kg} / \mathrm{m}^{3}\right)\end{array}$ & E1(MPa) & E2(MPa) & E3(MPa) & $\mu 12$ & $\mu 13$ & $\mu 23$ & G12 & G13 & G23 \\
\hline $\begin{array}{c}\text { Medium density } \\
\text { fiberboard } \\
\text { (MDF) }\end{array}$ & 710 & \multicolumn{3}{|c|}{3035} & \multicolumn{3}{|c|}{0,38} & \multicolumn{3}{|c|}{1099,75} \\
\hline $\begin{array}{c}\text { Japanese white } \\
\text { birch wood }\end{array}$ & 620 & 9702 & 1955 & 832 & 0,55 & 0,46 & 0,35 & 609 & 218 & 971 \\
\hline
\end{tabular}




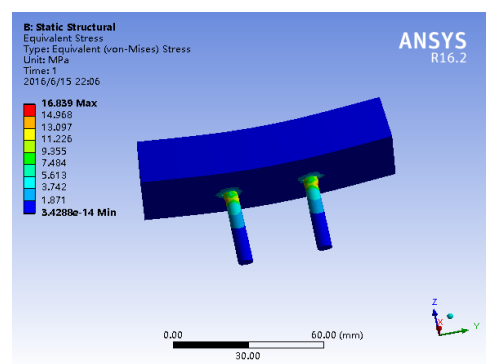

(a)

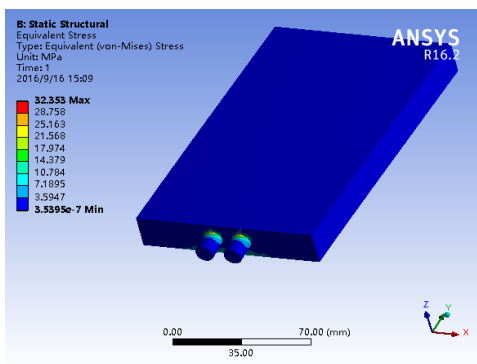

(b)

Figure 6. Equivalent displacement of tensile strength (a) and bending strength (b) using ANSYS.

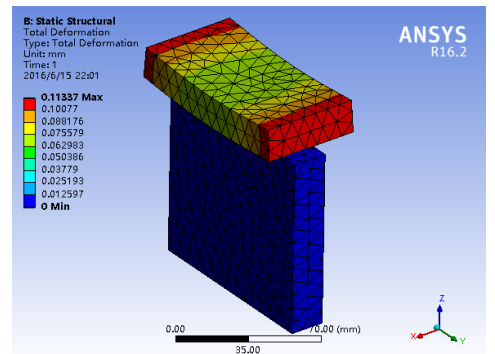

(a)

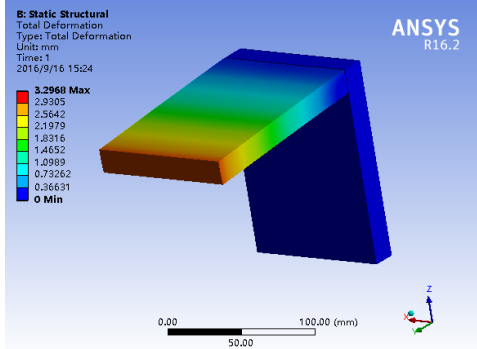

(b)

Figure 7. Equivalent stress of tensile strength (a) and bending strength (b) using ANSYS.

According to the material parameters in Table 7, the equivalent displacement and equivalent stress distribution of tensile and bending strengths of double dowel T-shaped and L-shaped joints constructed of medium density fiberboard based on ANSYS were obtained as shown in Figure 6 and Figure 7. The main modeling parameters and settings are as follows: The fits of tensile and bending simulation experiments are 0,2 and $0,1 \mathrm{~mm}$ respectively. Friction is set to rough properties, and as a result samples have rough contact surfaces. The mounting stresses before loading have not been taken into account in this simulation test. The vertical member is set to be fixed, and the transverse member is applied to load of $150 \mathrm{~N}$. Dowels made of Japanese white birch are nonlinear materials, which leads to the finite element method for this nonlinear model in this paper. Likewise, the simulation's calculated results of tensile and bending strengths tests are shown in Table 8 and Table 9.

Table 8. Simulation results of tensile strength tests based on ANSYS.

\begin{tabular}{|c|c|c|}
\hline Trial No. & $\begin{array}{c}\text { Equivalent Displacement Maximum } \\
(\mathrm{mm})\end{array}$ & Equivalent Stress Maximum (MPa) \\
\hline 1 & 1,1337 & 16,839 \\
\hline 2 & 0,986 & 14,245 \\
\hline 3 & 1,11297 & 7,5874 \\
\hline 4 & 1,0947 & 13,173 \\
\hline 5 & 0,67017 & 6,8364 \\
\hline 6 & 1,0986 & 11,194 \\
\hline 7 & 0,85212 & 15,875 \\
\hline 8 & 1,2457 & 19,429 \\
\hline 9 & 1,1018 & 11,34 \\
\hline
\end{tabular}


Table 9. Simulation results of bending strength tests based on ANSYS.

\begin{tabular}{|c|c|c|}
\hline Trial No. & $\begin{array}{c}\text { Equivalent Displacement Maximum } \\
(\mathrm{mm})\end{array}$ & Equivalent Stress Maximum (MPa) \\
\hline 1 & 1,8745 & 14,544 \\
\hline 2 & 2,3684 & 19,991 \\
\hline 3 & 2,4608 & 21,157 \\
\hline 4 & 2,4915 & 23,829 \\
\hline 5 & 4,1531 & 50,407 \\
\hline 6 & 6,0585 & 80,247 \\
\hline 7 & 3,9888 & 42,535 \\
\hline 8 & 5,6484 & 64,846 \\
\hline 9 & 3,2969 & 32,354 \\
\hline
\end{tabular}

For tensile strength tests, the equivalent displacement maximum and equivalent stress maximum appeared in the 8 th trial, which reflects the strength of double dowel T-shaped joints constructed of medium density fiberboard reaching its maximum, as shown in Table 8. Therefore, the optimum parameters for double dowel T-shaped joints constructed of medium density fiberboard are use of $10 \mathrm{~mm}$ diameter dowels $0,2 \mathrm{~mm}$ overlap between dowel and MDF and $64 \mathrm{~mm}$ dowel spacing. Likewise, for bending strength tests, the equivalent displacement maximum and equivalent stress maximum appeared in the 6th trial, which reflects the strength of double dowel L-shaped joints constructed of medium density fiberboard reaching its maximum, as shown in Table 9. Therefore, the optimum parameters for double dowel L-shaped joints constructed of medium density fiberboard are use of $10 \mathrm{~mm}$ diameter dowels $0,1 \mathrm{~mm}$ overlap between dowel and MDF and 48mm dowel spacing.

\section{CONCLUSIONS}

The tensile strength of dowel-MDF T-shaped joints depends on gap or overlap between dowel and fiberboard, dowel spacing and dowel diameter, in that order. The bending strength of dowel-MDF L-shaped joints depends on dowel diameter, dowel spacing and gap or overlap between dowel and fiberboard, in that order.

The optimum parameters for double dowel T-shaped joints constructed of medium density fiberboard are use of $10 \mathrm{~mm}$ diameter dowels, $0,2 \mathrm{~mm}$ overlap between dowel and MDF and $64 \mathrm{~mm}$ dowel spacing. The optimum parameters for double dowel L-shaped joints constructed of medium density fiberboard are use of $10 \mathrm{~mm}$ diameter dowels $0,1 \mathrm{~mm}$ overlap between dowel and MDF and $48 \mathrm{~mm}$ dowel spacing.

The dowel joint properties could be simulated under the same condition like experiment with the help of the finite element software.

\section{ACKNOWLEDGMENTS}

This research is supported by the Open Research Subject of Key Laboratory (Research Base) of Research Center of Industry Design (Grant No. GY-15ZD-01), Modern Design and Culture Research Center of Sichuan Provincial Key Research Base of Philosophy and Social Sciences (Grant No. MD15E017) and Key Research Project of Double Support Program for Art Special Project in Sichuan Agricultural University. This research was carried out at the Key Laboratory of Wood Industry and Furniture Engineering of Sichuan Provincial Colleges and Universities, Sichuan Agricultural University. 


\section{REFERENCES}

Abdolzadeh, H.; Ebrahimi, G.; Layeghi, M.;Ghassemieh, M. 2015. Analytical and experimental studies on stress capacity with modified wood members under combined stresses. Maderas-Cienc Tecnol 17(2): 263-276.

Altinok, M.; Taş, H. H.; Çimen, M. 2009. Effects of combined usage of traditional glue joint methods in box construction on strength of furniture. Materials \& Design 30(8):3313-3317.

Apay, A. C. 2012. Finite element analysis of wooden chair strength in free drop. International Journal of Physical Sciences 7(7): 1105-1114.

Bardak, T.; Tankut, A. N; Tankut, N.; Aydemir, D.; Sozen, E. 2017. The bending and tension strength of furniture joints bonded with polyvinyl acetate nanocomposites. Maderas-Cienc Tecnol 19(1): 51-62.

Chen, X.Y. 2013. The Study on Joints Property of T-type and L-type on Double Dowel of Catalpa Wood Components. Master Thesis, Central South University of Forestry and Technology, Changsha, China.

China National Standard System (GB). 1995. Method for determination of the modulus of elasticity in compressive parallel to grain of wood. GB/T15777:1995, China.

China National Standard System (GB). 2009. General requirements for physical and mechanical tests of wood. GB/T 1928:2009, China.

Dar, F. H.; Meakin, J. R.; Aspden, R. M. 2002. Statistical methods in finite element analysis. Journal of biomechanics 35(9):1155-1161.

Dong,H.G; Shao,Z.P. 2007. Strength Analysis of Dowels in Solid Wood Furniture. China Wood Industry 21(2):38-40.

Eckelman, C. A. 1970. The stiffness matrix method of furniture frame analysis. Wood Science 2(4):221-231.

He, F. M. 2008. Analysis and Optimization of Structure Strength in Panel-type Furniture Based on ANSYS. Ph.D. Thesis, Northeast Forestry University, Harbin, China.

Ke, Q.; Lin, L.; Chen, S.; Zhang, F.; Zhang, Y. 2016. Optimization of 1-shaped corner dowel joint in pine using finite element analysis with taguchi method. Wood Research 61(2): 243-254.

Liu,W.Q.1993. Furniture mechanics. Northeast Forestry University Press, Harbin, China.

Liu, W; Eckelman, C. A. 1998. Rational design of multi-dowel corner joints in case construction. Forest Products Journal 48(1):93-95.

Mackerle, J. 2005. Finite element analyses in wood research: a bibliography. Wood Science and Technology 39(7): 579-600.

Mayo, J. 2015. Solid Wood: Case Studies in Mass Timber Architecture, Technology and Design. Routledge Press, London, U.K.

Nicholls, T.; Crisan, R. 2002. Study of the stress-strain state in corner joints and box-type furniture using Finite Element Analysis (FEA). European Journal of Wood and Wood Products 60(1):66-71.

Smardzewski, J. 1998. Numerical analysis of furniture constructions. Wood Science and Technology 32(4): 273-286.

Smardzewski, J.; Rzepa, B.; Kıliç, H. 2015. Mechanical Properties of Externally Invisible Furniture Joints Made of Wood-Based Composites. BioResources 11(1): 1224-1239. 
Sjödin, J.; Serrano, E.; Enquist, B. 2008. An experimental and numerical study of the effect of friction in single dowel joints. Holz als Roh-und Werkstoff 66(5):363-372.

Zhang, J; Eckelman, C. A. 1993. The bending moment resistance of single-dowel corner joints in case construction. Forest Products Journal 43(6):19-24.

Zhang, J; Eckelman, C. A. 1993. Rational design of multi-dowel corner joints in case construction. Forest Products Journal 43(11,12):52-58.

Zhang, J; Quin, F.; Tackett, B. 2001. Bending strength and stiffness of two-pin dowel joints constructed of wood and wood composites. Forest Products Journal 51(2):29-35. 